Short Communication

\title{
Boredom and problematic Facebook use in adolescents: What is the relationship considering trait or state boredom?
}

\author{
Maria Anna Donati *, Carola Beccari, Caterina Primi \\ Department of Neuroscience, Psychology, Drug, and Child's Health, Section of Psychology, University of Florence, Florence, Italy
}

\section{A R T I C L E I N F O}

\section{Keywords:}

Trait boredom

Problematic Facebook use

State boredom

Adolescents

Mediation

Indirect effect

\begin{abstract}
A B S T R A C T
Boredom is an unpleasant experience caused by the lack of being engaged in satisfying activities. It can be caused by external circumstances (state boredom, SB) or by individual determinants (trait boredom, TB). Although several studies have attested the impact of boredom on adolescents' risk-taking behaviours, the relationships between boredom and problematic Facebook use (PFU), which has grown exponentially among adolescents, have not been deeply analysed to date. This study aimed at exploring a possible mechanism through which TB, PFU, and SB are related. We hypothesised and tested the mediating role of PFU in the relationship between TB and SB. Participants were 204 Italian adolescents $\left(57 \%\right.$ male, $\left.M_{\mathrm{age}}=17.13, S D=1.61\right)$. Analyses showed a significant positive indirect effect of TB on SB through PFU that acted as a mediator. Specifically, individual sensitivity to boredom may enhance the likelihood that teenagers employ Facebook excessively and in addictive way; in turn, PFU may enhance adolescents' situational experience of boredom. Although preliminary, findings indicate the need to further investigate the relationship between TB, PFU, and SB in youth.
\end{abstract}

\section{Introduction}

Boredom, characterised by unpleasant feelings, lack of motivation, and low physiological arousal, is widespread among young people (Biolcati et al., 2018). When boredom is the result of individual determinants, it can be viewed as a personality characteristic (trait boredom, TB; Farmer \& Sundberg, 1986) defined as the proneness to experience boredom in several situations. Alternatively, when boredom is experienced as a result of external circumstances, it is considered situation-dependent and conceptualised as the actual subjective experience of boredom in a given moment (state boredom, SB; Neu, 1998). Although with different phenomenologies and origins, there is a positive relationship between TB and SB as high levels of boredom susceptibility are related to a higher likelihood of experiencing momentary boredom (Mercer-Lynn et al., 2014).

It is well-known that youth with high level of TB are more likely to engage in unhealthy behaviours related to substances, such as drug use (Weybright et al., 2015) and alcohol abuse (Biolcati et al., 2018), and also non-substance addictive behaviours, such as problematic Internet use (Chou et al., 2018), social network addiction (Bai et al., 2021), and problematic smartphone use (Hong et al., 2020). The majority of these studies considered the association of TB with at-risk behaviours. In detail, with Italian adolescents, Biolcati et al. (2018) found that youth with high boredom proneness more frequently consumed strong drinks and binge drank than non-bored adolescents. Considering adolescents with attention-deficit/hyperactivity disorder, it has been shown that higher levels of TB were associated with a higher risk of Internet addiction; in particular, higher scores for lack of external stimulation were associated with a high tendency to engage in online gaming, whereas higher scores for lack of internal stimulation were associated with a low tendency to engage in online studying (Chou et al., 2018). Research also suggests that problematic use of social media positively predicts boredom susceptibility which, in turn, has a negative predictive effect on subjective wellbeing (Bai et al., 2021), and that autonomy need dissatisfaction affects problematic smartphone use through TB (Hong et al., 2020).

Only one of these studies explored the mechanisms of the relationship between boredom and unhealthy adolescent behaviours distinguishing between TB and SB. Specifically, using longitudinal data from South African adolescents, Weybright and colleagues (2015) found that the association between SB and substance use was even stronger for adolescents with high levels of TB.

\footnotetext{
* Corresponding author at: Department of Neuroscience, Psychology, Drug, and Child's Health, Section of Psychology, University of Florence, via di San Salvi 12 Padiglione 26, 50135 Firenze, Italy.

E-mail address: mariaanna.donati@unifi.it (M.A. Donati).
} 
Moreover, any evidence exists about its relationship with problematic Facebook use (PFU).

Among the social networking sites (SNSs), Facebook is the most commonly used (https://wearesocial.com/it/blog/2020/01/repo rt-digital-2020-i-dati-global), with adolescents spending from two to four hours a day on Facebook (e.g., Lai et al., 2018). The excessive use of Facebook can become problematic. Although different conceptualisations exist, PFU is defined as Facebook use (FU) that creates problems in users' life, such as psychological, emotional, social, or school difficulties (Marino et al., 2018). Overall, the worldwide prevalence of PFU ranges between 2 and 10\% in adolescents (Marino et al., 2018), with some studies showing higher prevalence rates (e.g., Mamun \& Griffiths, 2019).

Following the above cited studies with adolescents (Bai et al., 2021; Biolcati et al., 2018; Chou et al., 2018; Hong et al., 2020; Weybright et al., 2015) and recent studies with adults indicating that boredom proneness is related to problematic smartphone use (Elhai et al., 2017), Internet control disorder (Brand et al., 2019; Wegmann et al., 2018), and to longer sessions on Facebook (Caci et al., 2014), we hypothesised that TB would be positively related to PFU in youth.

We also predicted that PFU would be positively related to SB. Indeed, consistent with the fact that problematic social media use is associated with several adverse psychological effects (e.g., Brailovskaia et al., 2019; Duradoni et al., 2020), it has been shown that PFU is related to a variety of impairments in psychological wellbeing, life satisfaction, social relationships, and school engagement in adolescents (e.g., Demirci et al., 2020). Marino and colleagues (2018) evidenced the potential risks of PFU for mental health in youth, finding a positive correlation with psychological distress and a negative correlation with wellbeing. Within the conceptualisation of psychological distress, an increasing number of studies also include SB (e.g., Chao et al., 2020; Tutzer et al., 2020), as it is associated with maladaptive states by reducing attention control and monitoring (Yakobi et al., 2021). Thus, it has been suggested that PFU can have a negative effect on adolescents' negative affect (Kenney, 2018).

Taking together all the premises, this study was aimed at investigating a possible mechanism through which TB, PFU, and SB are related. A simple mediation model was hypothesised and tested, predicting that a) TB would be positively related to PFU, in line with previous studies with adolescents regarding unhealthy behaviours (Bai et al., 2021; Biolcati et al., 2018; Chou et al., 2018; Hong et al., 2020; Weybright et al., 2015) and with adults concerning Facebook use (Caci et al., 2014); b) that PFU, in turn, would be positively associated with SB, consistent with the relationship between PFU and psychological distress (e.g., Demirci et al., 2020; Marino et al., 2018), among which high levels of SB can be considered (Chao et al., 2020; Tutzer et al., 2020); c) that PFU would be a mediator of the positive relationship between TB and SB (Mercer-Lynn et al., 2014), predicting that a high individual sensitivity to boredom may enhance the likelihood of employing Facebook excessively and in addictive way and that, in turn, PFU may enhance adolescents' situational experience of boredom.

\section{Material and methods}

\subsection{Participants and procedure}

Participants were 204 adolescents (57\% male, $M_{\mathrm{age}}=17.13, S D=$ 1.61) attending a public high school in Italy. A study protocol which explained the study's aim and methodology was approved by the institutional review board of the school. The students received an information sheet, which assured them that the data obtained would be handled confidentially and anonymously, and they were asked to give written informed assent. Parents of minors were required to provide consent. In each class, participants were divided into two random groups that filled out the protocol in counterbalanced order. Each participant individually completed the scales during class time under the supervision of trained
Table 1

Intercorrelations, means, and standard deviations of the study variables.

\begin{tabular}{lclc}
\hline Variables & 1. & 2. & 3. \\
\hline 1. Trait boredom & - & & \\
2. Problematic Facebook use & $0.23^{* *}$ & - & \\
3. State boredom & $0.43^{* *}$ & $0.25^{* *}$ & - \\
$M$ & 18.61 & 0.91 & 28.47 \\
$S D$ & 6.31 & 0.14 & 9.01 \\
\hline
\end{tabular}

Notes: $\mathrm{n}=169 * * p<.01$.

research assistants. Answers were collected in a paper-and-pencil format. Data collection occurred in 2018 and it was completed in about $30 \mathrm{~min}$.

\subsection{Measures}

Adolescents were asked to indicate how many hours per day and how many days per week they used Facebook; how often (never, few times, many times) they used the listed devices (computer, tablet, console, smartphone) to use Facebook; how often (never, few times, many times) they used Facebook in the places indicated (at home, at school, not in a specific place); and the reasons underlying their FU.

The Bergen Facebook Addiction Scale (BFAS; Andreassen et al., 2012; Italian version: Soraci et al., 2020) contains six Likert-type items with a five-point scale ranging from 1 (very rarely) to 5 (very often) and related to the last year. A score of 3 or more in response to four items indicates PFU (Andreassen et al., 2012). This scale resulted to be adequate to measure PFU among Italian youth (Primi et al., 2021) $(\alpha=0.71)$.

The Short Boredom Proneness Scale (SBPS; Struk et al., 2015) contains eight Likert-type items rated on a seven-point scale ranging from 1 (completely disagree) to 7 (totally agree) and related to their usual everyday life. As the SBPS has never been psychometrically analysed in adolescents, we preliminarily investigated its psychometric properties in this age group (see Supplementary Material).

The Multidimensional State Boredom Scale - Short Form (MSBS-SF; Hunter et al., 2015) investigates the actual experience of boredom in a given moment, regardless of the context. Thus, adolescents were asked to respond by thinking to how they felt in the moment of the test administration at school. It has been adapted to Italian adolescents (Donati et al., 2019). It contains eight items evaluated on a seven-point Likert scale ranging from 1 (strongly disagree) to 7 (strongly agree) ( $\alpha=$ 0.73).

\section{Results}

Ninety-three percent of adolescents used SNSs $(n=190)$, and $89 \%$ of them $(\mathrm{n}=170)$ used Facebook, on which they spent on average $3 \mathrm{~h}$ a day $(M=3.28 ; S D=3.9)$. The devices on which teenagers use Facebook were smartphones (99\%), tablet (32\%), computers (29\%), and laptops (40\%). They usually used Facebook at home (99\%) and at school (83\%), and motivated by spending time (95\%), having fun (66\%), maintaining relationships (43\%), being in company (15\%), and escaping from problems and worries (11\%). Fifteen percent of adolescents met the criteria for PFU. Among those who used Facebook, one subject had more than $10 \%$ of missing values on the BFAS. We excluded this case (Kline, 2010). The same criterion was adopted for the other scales (12 cases deleted at the SBPS, 15 at MSBS). For cases with less than $10 \%$ of missing values, these were replaced with the subject's mean in that subscale. Thus, the subsequent analyses were conducted with participants having all the variable scores $(n=169)$.

The BFAS total scores distribution was significantly different from the normal (Shapiro-Wilk test $=0.76, d f=164, p<.001$ ). Thus, a $\log$ transformation was applied. Scores ranged from 0.78 to 1.41 .

Preliminarily, we analysed Pearson's correlations among the variables, adjusting the level of significance by Bonferroni correction to 


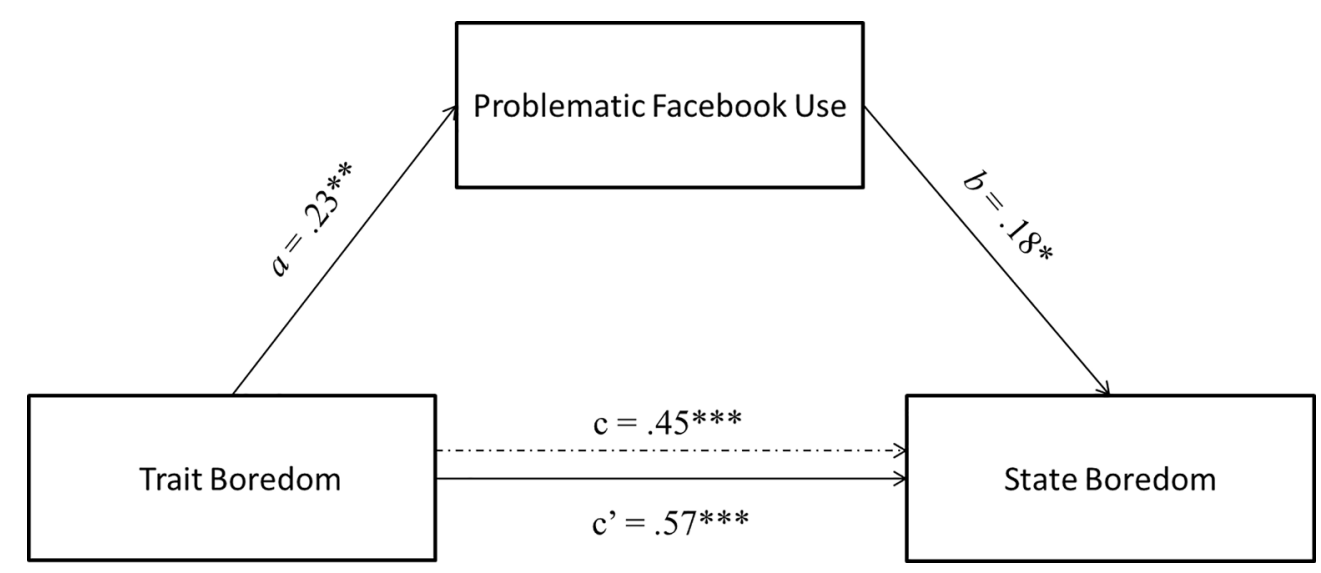

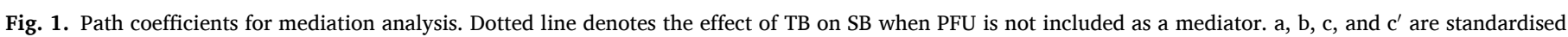
ordinary least squares (OLS) regression coefficients. Note: ${ }^{* * *} \mathrm{p}<.001{ }^{* *} \mathrm{p}<.01 * \mathrm{p}<.05$.

$0.017(0.05 / 3)$. It was confirmed that TB was positively related to SB and PFU, which, was also linked to SB (Table 1). All the correlations were under the significance level after the Bonferroni correction.

To further understand the mechanism underlying the relationship among these variables, we used the INDIRECT macro in SPSS (Hayes, 2013), which tested the hypothesised mediation model using the bootstrapping procedure (with 5000 bootstrap samples) to estimate the $95 \%$ CI (Preacher \& Hayes, 2008). As shown in Fig. 1, the mediation model was estimated to derive the total, direct, and indirect effects of TB on SB, through PFU. We estimated the indirect effect of TB on SB, quantified as the product of the ordinary least squares (OLS) regression coefficient estimating PFU from TB (i.e. Path $a$ in Fig. 1) and the OLS regression coefficient estimating SB from PFU controlling for TB (i.e. Path $b$ in Fig. 1). A bias-corrected bootstrap 95\% CI for the product of these paths that does not include zero provides evidence of a significant indirect effect (Hayes, 2013; Preacher \& Hayes, 2008). The results showed a significant positive total effect of TB on SB (i.e. Path $c$ in Fig. 1), a significant positive direct effect of TB on SB (i.e. Path $c^{\prime}$ in Fig. 1), and a significant positive indirect effect of TB on SB through PFU (point estimate $=0.06,95 \%$ CI $[0.002,0.131])$.

\section{Discussion}

Although preliminarily, this is the first study to investigate TB, PFU, and $\mathrm{SB}$ in adolescents and, specifically, to provide empirical evidence that PFU can be considered as an intermediary variable in the relationship between TB and SB. In more detail, considering the different links included in the mediation model, this study shows that TB is positively associated with PFU. Thus, consistent with studies referring to other risky behaviours in adolescents (e.g., Bai et al., 2021; Biolcati et al., 2018; Chou et al., 2018; Hong et al., 2020; Weybright et al., 2015), boredom susceptibility can be considered as a risk factor for PFU in youth. This result is also consistent with the suggested hypothesis that boredom may function as a call to action (e.g., Danckert \& Merrifield, 2018; Elpidorou, 2018). Moreover, we found that both TB and PFU have significant and positive effects on SB. These relationships confirm that also in adolescents high levels of TB predispose to higher susceptibility to SB (Mercer-Lynn et al., 2014) and suggest that PFU has an impact on adolescents' negative affect, as previously suggested (Kenney, 2018). This result should be further analysed as this was a cross-sectional study with a relatively low sample size. However, it is in line with recent studies that show that problematic social media use longitudinally predicts negative states (Kil et al., 2021; Nowland et al., 2018).

More importantly, we demonstrated that PFU mediates the relationship between TB and SB in adolescents; that is, higher levels of individual sensitivity to boredom may enhance the likelihood that adolescents employ Facebook excessively and in addictive way; in turn,
PFU may enhance adolescents' situational experience of boredom. This result can be profitably considered when planning educational interventions with adolescents that need theoretical models to be planned and evaluated. Indeed, in a preventive perspective, we should consider that, among the reasons that motivate teenagers to use Facebook, there is also escaping from boredom (Lampe et al., 2008; Ryan et al., 2014). As Facebook provides plenty of different stimuli, it can be assumed that bored juveniles might consider Facebook as an ideal place to pass time and fight boredom. Moreover, the specific effect of PFU in increasing adolescents' SB, controlling for TB, should be considered with attention as susceptibility to SB has negative effects on students' cognition, motivation, performance, and learning (Pekrun et al., 2010), and experiencing SB during free time is associated with drug use (Weybright et al., 2015), Internet addiction (Lin et al., 2009), and SNS addiction (Stockdale \& Coyne, 2020).

Although preliminarily, this study opens up future and deeper investigations that should better analyse other potential mediation models involving TB, PFU, and SB, and by taking into account sex and age differences. Finally, it would be also interesting to conduct experimental studies to investigate how TB is related to different types of Facebook engagement (for instance, passive or active forms of Facebook usage; Orosz et al., 2016), and by focusing on participants' momentary SB and subsequent intention to risk-taking decisions/behaviours.

\section{Declaration of Competing Interest}

The authors declare that they have no known competing financial interests or personal relationships that could have appeared to influence the work reported in this paper.

\section{Acknowledgment}

The authors wish to thank all the high school students who have participated in this study, their school's principals and teachers, and their parents.

\section{Role of funding sources}

No funding for this study was provided.

\section{Appendix A. Supplementary data}

Supplementary data to this article can be found online at https://doi. org/10.1016/j.addbeh.2021.107132. 


\section{References}

Andreassen, C. S., Torsheim, T., Brunborg, G. S., \& Pallesen, S. (2012). Development of a Facebook Addiction Scale. Psychological Reports, 110(2), 501-517. https://doi.org/ 10.2466/02.09.18.PR0.110.2.501-517

Bai, J., Mo, K., Peng, Y., Hao, W., Qu, Y., Lei, X., \& Yang, Y. (2021). The relationship between the use of mobile social media and subjective well-being: The mediating effect of boredom proneness. Frontiers in Psychology, 11, Article 568492. https://doi. org/10.3389/fpsyg.2020.568492

Biolcati, R., Mancini, G., \& Trombini, E. (2018). Proneness to boredom and risk behaviors during adolescent's free time. Psychological Reports, 121(2), 303-323. https://doi. org/10.1177/0033294117724447

Brailovskaia, J., Rohmann, E., Bierhoff, H.W., Magraf, J., \& Kollner, V. (2019). Relationships between addictive Facebook use, depressiveness, insomnia, and positive mental health in an inpatient sample: A German longitudinal study. Journal of Behavioral Addictions, 8(4), 703-713. 10.1556/2006.8.2019.63.

Brand, M., Wegmann, E., Stark, R., Muller, A., Wolfling, K., Robbins, T. W., \& Potenza, M. N. (2019). The interaction of Person-Affect-Cognition-Execution (IPACE) model for addictive behaviors: Update, generalization to addictive behaviors beyond internet-use disorders, and specification of the process character of addictive behaviors. Neuroscience \& Biobehavioral Reviews, 104, 1-10. https://doi.org/ 10.1016/j.neubiorev.2019.06.032

Caci, B., Cardaci, M., Tabacchi, M. E., \& Scrima, F. (2014). Personality variables as predictors of Facebook usage. Psychological Report, 114(2), 528-539. https://doi. org/10.2466/21.09.PR0.114k23w6

Chao, M., Chen, X., Liu, T., Yang, H., \& Hall, B. J. (2020). Psychological distress and state boredom during the COVID-19 outbreak in China: The role of meaning in life and media use. European Journal of Psychotraumatology, 11(1), 1769379. https://doi.org/ 10.1080/20008198.2020.1769379

Chou, W. J., Chang, Y. P., \& Yen, C. F. (2018). Boredom proneness and its correlation with Internet addiction and Internet activities in adolescents with attention deficit/ hyperactivity disorder. The Kaohsiung Journal of Medical Science, 34(8), 467-474. https://doi.org/10.1016/j.kjms.2018.01.016

Danckert, J., \& Merrifield, C. (2018). Boredom, sustained attention and the default mode network. Experimental Brain Research Journal, 236(9), 2507-2518. https://doi.org/ 10.1007/s00221-016-4617-5

Demirci, I., Usta, F., Yildiz, B., \& Dermirtas, A. S. (2020). School burnout and school engagement in adolescents: The mediator and moderator role of Facebook addiction. Education and Science, Early Release, 1-19. https://doi.org/10.15390/EB.2020.8377

Donati, M. A., Borace, E., Franchi, E., \& Primi, C. (2019). Using the short form of the MSBS to assess state boredom among adolescents: Psychometric evidence by applying Item Response Theory. Assessment, 28(3), 928-941. https://doi.org/ $10.1177 / 1073191119864655$

Duradoni, M., Innocenti, F., \& Guazzini, A. (2020). Well-being and social media: A systematic review of Bergen Addiction Scales. Future Internet, 12(2), 24. https://doi. org/10.3390/fi12020024

Elhai, J. D., Vasquez, J. K., Lustgarten, S. D., Levine, J. C., \& Hall, B. J. (2017). Proneness to boredom mediates relationships between problematic smartphone use with depression and anxiety severity. Social Science Computer Review, 20(10), 1-14. https://doi.org/10.1177/0894439317741087

Elpidorou, A. (2018). The good of boredom. Philosophical Psychology, 31(3), 323-351. https://doi.org/10.1080/09515089.2017.1346240

Farmer, R., \& Sundberg, N. D. (1986). Boredom proneness - the development and correlates of a new state. Journal of Personality Assessment, 50, 4-17. https://doi.org/ 10.1207/s15327752jpa5001_2

Hayes, A. F. (2013). Introduction to mediation, moderation, and conditional process analysis: A regression- based approach. New York, NY: Guilford Press.

Hong, W., Liu, E., Ding, Y., Zhen, R., Jiang, R., \& Fu, X. (2020). Autonomy need dissatisfaction in daily life and problematic mobile phone use: The mediating roles of boredom proneness and mobile phone gaming. International Journal of Environmental Research and Public Health, 17(15), 5305. https://doi.org/10.3390/ijerph17155305

Hunter, J. A., Dyer, K. J., Cribbie, R. A., \& Eastwood, J. D. (2015). Exploring the utility of the multidimensional state boredom scale. European Journal of Psychological Assessment, 32, 241-250. https://doi.org/10.1027/1015-5759/a000251

Kenney, S. A. (2018). Impact of type of Facebook use on negative affect. Available form ProQuest Dissertation. St. Louis, USA: The George Washington University.

Kil, N., Kim, J., Park, J., \& Lee C. (2021). Leisure boredom, leisure challenge, smartphone use, and emotional distress among U.S. college students: are they interrelated? Leisure Studies. 10.1080/02614367.2021.1931414.

Kline, R. B. (2010). Principles and practice for structural equation modelling (3rd ed.). Guildford Press: New York, NY.
Lai, H., Hsieh, P., \& Zang, R. (2018). Understanding adolescent students' use of Facebook and their subjective wellbeing: A gender-based comparison. Behavior \& Information Technology. https://doi.org/10.1080/0144929X.2018.1543452

Lampe, C., Ellison, N.B., \& Steinfield, C. (2008). Changes in use and perception of Facebook. In Begole, B., \& McDonald, D.W. (Eds.), The ACM 2008 conference, pp. 721-730. 10.1145/1460563.1460675.

Lin, C. H., Lin, S. L., \& Wu, C. P. (2009). The effects of parental monitoring and leisure boredom on adolescents' internet addiction. Adolescence, 44, 993-1004.

Mamun, M. A. A., \& Griffiths, M. D. (2019). The association between Facebook addiction and depression: A pilot survey study among Bangladeshi students. Psychiatry Research, 271, 628-633. https://doi.org/10.1016/j.psychres.2018.12.039

Marino, C., Gini, G., Vieno, A., \& Spada, M. M. (2018). The associations between problematic Facebook use, psychological distress and well-being among adolescents and young adults: A systematic review and meta-analysis. Journal of Affective Disorders, 226, 274-281. https://doi.org/10.1016/j.jad.2017.10.007

Mercer-Lynn, K. B., Bar, R. J., \& Eastwood, J. D. (2014). Causes of boredom: The person, the situation, or both? Personality and Individual Differences, 56, 122-126. https:// doi.org/10.1016/j.paid.2013.08.034

Neu, J. (1998). Boring from within: Endogenous versus reactive boredom. In W. F. Flack (Ed.), Emotions in Psychopathology: Theory and Research (pp. 158-170). Laird (London: Oxford University Press).

Nowland, R., Necka, E. A., \& Cacioppo, J. T. (2018). Loneliness and social internet use: Pathways to reconnection in a digital world? Perspectives in Psychological Science, 13, 70-87. https://doi.org/10.1177/1745691617713052

Orosz, G., Tóth-Király, I., \& Böthe, B. (2016). Four facets of Facebook intensity - The development of the Multidimensional Facebook Intensity Scale. Personality and Individual Differences, 100, 95-104. https://doi.org/10.1016/j.paid.2015.11.038

Pekrun, R., Goetz, T., Daniels, L. M., Stupnisky, R. H., \& Perry, R. P. (2010). Boredom in achievement settings: Exploring control-value antecedents and performance outcomes of a neglected emotion. Journal of Educational Psychology, 102, 531-549. https://doi.org/10.1037/a0019243

Preacher, K. J., \& Hayes, A. F. (2008). Asymptotic and resampling strategies for assessing and comparing indirect effects in multiple mediator models. Behavior Research Methods, 40(3), 879-891. https://doi.org/10.3758/BRM.40.3.879

Primi, C., Fioravanti, G., Casale, S., \& Donati, M. A. (2021). Measuring Problematic Facebook use among adolescents and young adults with the Bergen Facebook Addiction Scale: A psychometric analysis by applying Item Response Theory. International Journal of Environmental Research and Public Health, 18, 2979. https:// doi.org/10.3390/ijerph18062979

Ryan, T., Chester, A., Reece, J., \& Xenos, S. (2014). The uses and abuses of Facebook: A review of Facebook addiction. Journal of Behavioral Addictions, 3(3), 133-148. https://doi.org/10.1556/JBA.3.2014.016

Soraci, P., Ferrari, A., Barberis, N., Luvarà, G., Del Fante, E., \& Griffiths, M. D. (2020). Psychometric analysis and validation of the Italian Bergen Facebook Addiction Scale. International Journal of Mental Health and Addiction. https://doi.org/10.1007/ s11469-020-00346-5

Stockdale, L. A., \& Coyne, S. M. (2020). Bored and online: Reasons for using social media, problematic social networking site use, and behavioral outcomes across the transition from adolescence to emerging adulthood. Journal of Adolescence, 79, 173-183. https://doi.org/10.1016/j.adolescence.2020.01.010

Struk, A. A., Carriere, J. S. A., Cheyne, J. A., \& Danckert, J. (2015). A Short Boredom Proneness Scale: Development and psychometric properties. Assessment, 1-14. https://doi.org/10.1177/1073191115609996

Tutzer, F., Frajo-Apor, B., Pardeller, S., Plattner, B., Chernova, A., Haring, C., ... Hofer, A. (2020). Psychological distress, loneliness, and boredom among the general population of Tyrol, Austria during the Covid-19 pandemic. Frontiers in Psychiatry, 12, Article 691896. https://doi.org/10.3389/fpsyt.2021.691896ù

Wegmann, E., Ostendorf, S., Brand, M., \& Reed, P. (2018). Is it beneficial to use Internetcommunication for escaping from boredom? Boredom proneness interacts with cueinduced craving and avoidance expectancies in explaining symptoms of Internetcommunication disorder. PLOS ONE, 13(4), e0195742. https://doi.org/10.1371/ journal.pone.0195742

Weybright, E. H., Caldwell, L. L., Ram, N., Smith, E. A., \& Wegner, L. (2015). Boredom prone or nothing to do? Distinguishing between state and trait leisure boredom and its association with substance use in South African adolescents. Leisure Sciences, 37 (4), 311-331. https://doi.org/10.1080/01490400.2015.1014530

Yakobi, O., Boylan, J., \& Danckert, J. (2021). Behavioral and electroencephalographic evidence for reduced attentional control and performance monitoring in boredom. Psychophysiology, 58(6), Article e13816. https://doi.org/10.1111/psyp.13816 